\title{
Grid laser with modified pro re nata injection of bevacizumab and ranibizumab in macular edema due to branch retinal vein occlusion: MARVEL
} report no 2

\author{
This article was published in the following Dove Press journal: \\ Clinical Ophthalmology \\ 2 June 2016 \\ Number of times this article has been viewed
}

\author{
Raja Narayanan' \\ Bhavik Panchal' \\ Michael W Stewart ${ }^{2}$ \\ Taraprasad Das' \\ Jay Chhablani' \\ Subhadra Jalali' \\ Mohd Hasnat $\mathrm{Ali}^{3}$ \\ On behalf of MARVEL \\ study group
}

'Smt. Kanuri Santhamma Centre for Vitreo Retinal Diseases, LV Prasad Eye Institute, Hyderabad, India; ${ }^{2}$ Department of Ophthalmology, Mayo Clinic, Jacksonville, FL, USA; ${ }^{3}$ Department of Biostatistics, LV Prasad Eye Institute, Hyderabad, India
Correspondence: Raja Narayanan Smt. Kanuri Santhamma Centre for Vitreo Retinal Diseases, L V Prasad Eye Institute, L V Prasad Marg, Banjara Hills, Hyderabad, Telangana, 500 034, India Email narayanan@lvpei.org
Purpose: The purpose of this study was to prospectively study the efficacy of grid laser combined with intravitreal bevacizumab or ranibizumab in eyes with macular edema due to branch retinal vein occlusion.

Patients and methods: Treatment-naïve eyes were enrolled to receive injections of ranibizumab or bevacizumab. During the first 6 months, patients were evaluated monthly and injected if the best-corrected visual acuity changed by five or more letters or fluid was noted on spectral domain optical coherence tomography (OCT); during the next 6 months, patients were evaluated bimonthly and injected only if the best-corrected visual acuity decreased by five or more letters with the associated fluid. Grid laser photocoagulation was performed if there was fluid on OCT and was repeated if patients were eligible after a minimum interval of 3 months.

Results: The mean numbers of ranibizumab and bevacizumab injections were, respectively, $3.2 \pm 1.5$ and $3.0 \pm 1.4$ in the first 6 months and $0.3 \pm 0.6$ and $0.3 \pm 0.6$ in the last 6 months. Moreover, 55/75 (73.33\%) participants did not receive any injections in the last 6 months. The mean reductions in central retinal thickness at 12 months were $165.67 \mu \mathrm{m}(P<0.001 ; 95 \%$ confidence interval -221.50 to -135.0$)$ in the ranibizumab group and $184.78 \mu \mathrm{m}(P<0.001$; $95 \%$ confidence interval -246.49 to -140.0$)$ in the bevacizumab group $(P=0.079)$. More patients in the bevacizumab group compared to those in the ranibizumab group required rescue laser at 12 months (20 vs eleven; $P=0.06$ ).

Conclusion: Bimonthly evaluations after month 6 with very few pro re nata injections were effective in maintaining visual gains achieved during the first 6 months. Grid laser photocoagulation is effective in maintaining the vision even in the presence of fluid on OCT, although it's required more often in patients treated with bevacizumab.

Keywords: PRN dosing, grid laser, visual acuity, randomized clinical trial

\section{Introduction}

Branch retinal vein occlusion (BRVO) represents the second most common retinal vascular disorder, affecting $0.6 \%-1.1 \%$ of individuals over the age of 50 years. ${ }^{1,2}$ There is upregulation of numerous chemokines and cytokines, including interleukin-6, interleukin-8, monocyte chemotactic protein-1, soluble intercellular adhesion molecule-1, interferon-induced protein-10, platelet-derived growth factor-AA, vascular endothelial growth factor (VEGF), soluble VEGF receptor-1, and soluble VEGF receptor-2., ${ }^{3,4}$ VEGF plays a critical role in the formation of macular edema by acting on various pathways at the molecular and cellular levels..$^{5-7}$ 
Data from Phase III, randomized, controlled trials of eyes with macular edema due to BRVO showed that monthly intravitreal injections of ranibizumab (Lucentis ${ }^{\circledR}$; Genentech, Inc., South San Francisco, CA, USA) and aflibercept (Eylea ${ }^{\circledR}$; Regeneron, Tarrytown, NY, USA) inhibit the actions of VEGF and improve macular thickness and visual acuity (VA) better than sham/photocoagulation. ${ }^{8-10}$ The excess macular fluid resolves rapidly in the majority of drug-treated patients, and the average best-corrected visual acuity (BCVA) improves by +17.0 to +18.3 letters at 6 months. ${ }^{8,10}$ Unfortunately, a regimen of monthly intravitreal injections challenges compliance; so after the initial 6-month treatment period, ranibizumab for the treatment of macular edema following Branch Retinal Vein Occlusion: Evaluation of Efficacy and Safety (BRAVO) trial adopted a monthly pro re nata (PRN) strategy, ${ }^{9}$ whereas the study to assess the clinical efficacy and safety of intravitreal aflibercept injection in patients with BRVO (VIBRANT) extended the assessment and injection intervals to every 8 weeks. ${ }^{10}$ Patients in the BRAVO trial received six monthly injections after enrollment and 2.7 injections (mean) between months 6 and $12 .{ }^{9}$

Despite the impressive data from these trials, important questions regarding the treatment of BRVO remain. The optimal injection frequency of anti-VEGF drugs during the first year has not yet been established. Although most eyes initially do well with monthly dosing, PRN regimens have not been adequately studied and less frequent $P R N$ regimens that do not require monthly visits to physicians' offices have not been described.

Because of these unresolved issues, we designed the MARVEL study to answer two questions. We wanted to determine if PRN treatment regimen from baseline along with monthly visits for the first 6 months followed by bimonthly visits for the next 6 months could achieve BCVA improvements comparable to those in the Phase III trials. In the first MARVEL publication, ${ }^{11}$ we reported that monthly visits with PRN injections of either bevacizumab (Avastin ${ }^{\mathrm{TM}}$; $1.25 \mathrm{mg} / 0.05 \mathrm{~mL}$; Hoffman-La Roche Ltd., Basel, Switzerland) or ranibizumab (Lucentis ${ }^{\mathrm{TM}}$; $0.5 \mathrm{mg} / 0.05 \mathrm{~mL}$; Novartis International AG, Basel, Switzerland) significantly improve average BCVA $(+15.6$ letters or +18.1 letters, respectively) for 6 months. After the initial 6-month period in the MARVEL trial, we decreased the surveillance frequency to every 2 months, modified the treatment criteria, and continued to treat patients on a PRN basis. This study reports the average gains in BCVA and numbers of reinjections and laser sessions at 12 months.

\section{Patients and methods}

The local institutional review board (LEC-11-097) of L V Prasad Eye Institute approved the study. The study protocol adhered to the tenets of the Declaration of Helsinki, and all participants gave written informed consent before enrollment. The eligible patients were recruited from January 2012 through February 2013 at the L V Prasad Eye Institute, Hyderabad, India.

\section{Patient eligibility}

A detailed description of the methodology is given in MARVEL report number $1 .{ }^{11}$ Briefly, the key eligibility criteria included: 1) center-involving macular edema due to BRVO of $<9$ months duration; 2) minimum central retinal thickness (CRT) of $250 \mu \mathrm{m}$ on spectral domain optical coherence tomography (SD-OCT); and 3) best-corrected early treatment of diabetic retinopathy VA of 24-73 letters (20/40 to 20/320) in the study eye.

The key exclusion criteria included: 1) previous macular laser photocoagulation in the study eye; 2) use of intraocular or periocular corticosteroids in the study eye within the previous 3 months; and 3 ) previous treatment with anti-VEGF drugs in the study eye.

\section{Study design}

Subjects were randomized to one of the following treatment arms in a 1:1 ratio in block sizes of six: 1) $0.5 \mathrm{mg}$ ranibizumab intravitreally at baseline followed by monthly PRN injections and 2) $1.25 \mathrm{mg}$ bevacizumab intravitreally at baseline followed by monthly PRN.

At month 6, subjects were evaluated monthly and injected PRN according to the protocol retreatment criteria. From months 6 through 12, patients were evaluated every 2 months and injected PRN according to the modified retreatment criteria.

\section{Retreatment criteria for PRN dosing during the first 6 months}

During the first 6 months, subjects received additional injections of study drug if any of the following retreatment criteria were satisfied: 1) $>50 \mu \mathrm{m}$ increase in CRT compared to the thinnest previous measurement; 2) new or persistent cystoid retinal changes or subretinal fluid on SDOCT; 3) loss of five or more letters from the best previous BCVA measurement together with any increase in CRT; and 4) increase in five or more letters from the most recent BCVA measurement. 


\section{Retreatment criteria for PRN dosing during the last 6 months}

From months 6 through 12, subjects received additional injections of study drug only if there was a loss of five or more letters of BCVA together with fluid on SD-OCT.

\section{Rescue laser criteria}

Subjects in both treatment arms were eligible to receive modified macular grid laser photocoagulation if the following prespecified criteria were met: 1) $>50 \mu \mathrm{m}$ increase in CRT compared to the previous measurement and 2) persistent diffuse edema with CRT $\geq 250 \mu \mathrm{m}$. An anti-VEGF injection and laser were performed at the same visit only if the above rescue laser criteria were met and the BCVA decreased by five or more letters.

\section{Outcome measures}

The primary end point was the change in the BCVA score from baseline at month 12 versus month 6 . The secondary outcome measures included: 1) proportion of subjects who gained 15 letters or more in BCVA at 12 months and 2) change in CRT from baseline at month 12 .

\section{Statistical analysis}

Fisher's exact test was used to analyze categorical variables, and both Wilcoxon rank sum test and two-sample $t$-test were used to analyze continuous variables. The values of mean and standard deviation (SD) were reported. $P$-values and confidence intervals (CIs) were two sided, with a $P$-value of $<0.05$ considered significant. Data were analyzed using R software Version 3.1.2 (R Development Core Team, R Foundation for Statistical Computing, Vienna, Austria).

\section{Results}

Baseline characteristics of enrolled patients are summarized in Table 1. There were no significant differences in demographic or ocular characteristics between the study groups at baseline, except that there were significantly more females in the ranibizumab group. The BCVA letter scores (mean $\pm \mathrm{SD}$ ) were 52.8 \pm 14.4 letters and 56.1 \pm 10.0 letters $(P=0.32)$ and the mean baseline CRT was $445.6 \pm 119.5 \mu \mathrm{m}$ and $491.5 \pm 155.1 \mu \mathrm{m}(P=0.1)$ in the ranibizumab and bevacizumab groups, respectively. Most patients (ranibizumab: 31/37 [83.78\%]; bevacizumab: 29/38 [76.31\%]) completed the study.

\section{Functional outcomes at month 12}

Important primary and secondary outcomes at months 6 and 12 are listed in Table 2. At 12 months, the mean BCVAs were $71.7 \pm 14.7$ letters and $72.2 \pm 14.9$ letters (Snellen equivalent: 20/40 for each) in the ranibizumab and bevacizumab groups, respectively. The mean gains in BCVA from baseline were +18.9 letters $(P<0.001 ; 95 \% \mathrm{CI}+14.0$ to +22.5$)$ in the ranibizumab group and +16.1 letters $(P<0.001 ; 95 \% \mathrm{CI}+12.6$ to +19.5 ) in the bevacizumab group (Figure 1).

The proportions of patients who gained $\geq 15$ letters at 12 months (ranibizumab: 24 [64.9\%]; bevacizumab: $23[60.5 \%]$ ) were similar to those at 6 months (ranibizumab: 59.4\%; bevacizumab: $57.8 \% ; P=0.46$ and $P=0.77$, respectively). Importantly, 16 eyes in each group (ranibizumab: 43.24\%; bevacizumab: $42.11 \%$ ) gained 15 or more letters after the first injection $(P=1.0)$. One patient from each group lost more than five letters from the baseline BCVA, and no patient lost more than 15 letters.

Twenty-three $(62.16 \%)$ eyes in the ranibizumab group and $25(65.78 \%)$ in the bevacizumab group achieved final

Table I Baseline characteristics of enrolled patients

\begin{tabular}{|c|c|c|c|}
\hline Characteristic & Ranibizumab (n=37) & Bevacizumab $(n=38)$ & $P$-value \\
\hline Mean age, years $\pm S D$ & $52.9 \pm 8.5$ & $50.5 \pm 8.7$ & 0.23 \\
\hline \multicolumn{4}{|l|}{ Sex, n (\%) } \\
\hline Female & $22(59.46)$ & $12(3 \mid .58)$ & 0.02 \\
\hline Male & $15(40.54)$ & $26(68.42)$ & \\
\hline \multicolumn{4}{|l|}{ Preexisting conditions/comorbidities } \\
\hline Hypertension, n (\%) & $23(62.1)$ & 27 (7I.I) & 0.46 \\
\hline Diabetes mellitus, $\mathrm{n}(\%)$ & $7(18.9)$ & $10(26.3)$ & 0.58 \\
\hline Hyperlipidemia, n (\%) & II (29.7) & $14(36.8)$ & 0.62 \\
\hline Coronary artery disease, $\mathrm{n}(\%)$ & $2(5.4)$ & I (2.6) & 0.61 \\
\hline Stroke, n (\%) & $2(5.4)$ & $\mathrm{I}(2.6)$ & 0.61 \\
\hline \multicolumn{4}{|l|}{ Blood pressure, $\mathrm{mmHg}$} \\
\hline Systolic & $132.2 \pm 12.7$ & $137.4 \pm 19.9$ & 0.18 \\
\hline Diastolic & $86.1 \pm 9.4$ & $86.8 \pm 11.5$ & 0.77 \\
\hline
\end{tabular}

Abbreviation: SD, standard deviation. 
Table 2 The primary and secondary outcome measures at 6 months and 12 months

\begin{tabular}{|c|c|c|c|c|c|c|}
\hline & \multicolumn{3}{|c|}{ Ranibizumab $(n=37)$} & \multicolumn{3}{|c|}{ Bevacizumab $(n=38)$} \\
\hline & Baseline & 6 months & 12 months & Baseline & 6 months & 12 months \\
\hline BCVA (letters) ${ }^{\mathrm{a}}$ & $52.8 \pm 14.4$ & $70.9 \pm 13.4$ & $71.7 \pm 14.7$ & $56.1 \pm 10.0$ & $71.7 \pm 10.0$ & $72.2 \pm 14.9$ \\
\hline CRT $(\mu \mathrm{m})$ & $445.7 \pm 119.5$ & $268.6 \pm 99.5$ & $280.0 \pm 125.9$ & $491.6 \pm 155.1$ & $289.9 \pm 77.7$ & $306.8 \pm 116.3$ \\
\hline Injections (mean \pm SD) & NA & $3.2 \pm 1.5$ & $3.5 \pm 2.4$ & NA & $3.0 \pm 1.4$ & $3.3 \pm 2.1$ \\
\hline Lasers (n) & NA & Four grid & Eleven grid and two sectoral & NA & Eight grid & 20 grid and two sectoral \\
\hline
\end{tabular}

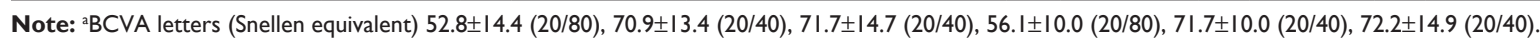

Abbreviations: BCVA, best-corrected visual acuity; CRT, central retinal thickness; SD, standard deviation; NA, not applicable.

visual acuities of $\geq 20 / 40$ ( $P=0.8$ ). No patient in either group suffered a BCVA $\leq 20 / 200$ at either 6 or 12 months.

\section{Anatomic outcomes at month 12}

The mean reductions in CRT at month 6 (ranibizumab: $-177.1 \mu \mathrm{m}$; bevacizumab: $-201.7 \mu \mathrm{m})$ were maintained at month 12 (ranibizumab: $-165.7 \mu \mathrm{m}$; bevacizumab: $-184.8 \mu \mathrm{m} ; P=0.84)$.

\section{Treatments}

\section{Mean numbers of injections}

The mean numbers of injections from baseline through 12 months (ranibizumab: $3.5 \pm 2.4$; bevacizumab: $3.3 \pm 2.1$; $P=0.8)$ changed a little from the 6-month totals ( $3.2 \pm 1.5$ and $3.0 \pm 1.4$ ), demonstrating that patients received an average of only 0.3 injections during the final 6 months of the study.

\section{Rescue laser treatment}

At 6 months, relatively a few patients had received rescue laser photocoagulation (ranibizumab: four (10.8\%); bevacizumab: eight (21.0\%); $P=0.34)$; however, more patients received laser between months 6 and 12 (ranibizumab: seven (18.91\%); bevacizumab: 12 (31.57\%); $P=0.19$ between the groups). At 12 months, more patients receiving bevacizumab than ranibizumab required macular laser ( 20 vs eleven; $P=0.06$ ). Two patients in each group received sector laser photocoagulation due to the development of neovascularization.

\section{Adverse events}

Ocular adverse events included the development of epiretinal membranes (ranibizumab: one; bevacizumab: three; $P=0.9$ ), progression of cataract (ranibizumab: two; bevacizumab: three), and elevation of intraocular pressure (bevacizumab: one) that was controlled with one topical medication. One patient receiving ranibizumab developed a BRVO in the fellow eye. None of the patients developed endophthalmitis.

Fifteen patients in the ranibizumab group and ten patients in the bevacizumab group developed hypertension during the study $(P=0.53)$. Two patients in the ranibizumab group were admitted to the hospital for a fractured foot and chikungunya fever. The important adverse events are listed in Table 3.

\section{Discussion}

Advances in laser photocoagulation and intravitreal pharmacotherapy over the past three decades have significantly improved the treatment of macular edema due to BRVO. The Branch Vein Occlusion Trial was the first to show

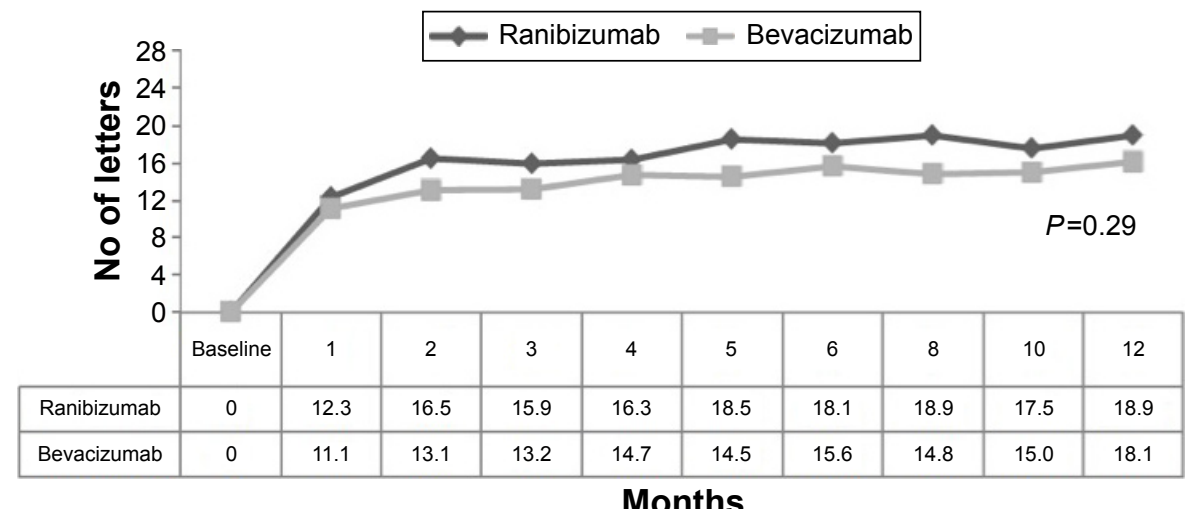

Figure I Gain in letters from baseline to I year comparing ranibizumab and bevacizumab.

Note: Data points represent the mean gain in BCVA.

Abbreviation: BCVA, best-corrected visual acuity. 
Table 3 Observed adverse events during the 12-month trial

\begin{tabular}{lll}
\hline & $\begin{array}{l}\text { Ranibizumab } \\
(\mathbf{n}=\mathbf{3 7})\end{array}$ & $\begin{array}{l}\text { Bevacizumab } \\
(\mathbf{n}=\mathbf{3 8 )}\end{array}$ \\
\hline Cataract, n (\%) & $2(5.4)$ & $3(7.9)$ \\
Conjunctivitis, n (\%) & $3(8.1)$ & $\mathrm{I}(2.6)$ \\
Hypertension, n (\%) & $\mathrm{I} 5(40.5)$ & $\mathrm{I} 0(26.3)$ \\
Jaundice, n (\%) & $2(5.4)$ & $0(0.0)$ \\
ERM, n (\%) & $\mathrm{I}(2.7)$ & $3(7.9)$ \\
Increase in IOP, n (\%) & $0(0.0)$ & $\mathrm{I}(2.6)$ \\
Increase in creatinine, n (\%) & $\mathrm{I}(2.7)$ & $0(0.0)$ \\
Hyperlipidemia, n (\%) & $5(13.5)$ & $\mathrm{I} 0(26.3)$ \\
Vitreous hemorrhage, n (\%) & $\mathrm{I}(2.7)$ & $0(0.0)$ \\
\hline
\end{tabular}

Abbreviations: ERM, epiretinal membrane; IOP, intraocular pressure.

that modified grid laser photocoagulation improves VA better than observation. ${ }^{12}$ Pilot studies performed nearly two decades later suggested that intravitreal triamcinolone effectively resolves macular edema and improves VA, ${ }^{13,14}$ but the SCORE trial found no difference in VA between laser photocoagulation and triamcinolone. ${ }^{15}$ However, there was a much higher rate of cataract and glaucoma with the $4 \mathrm{mg}$ dose of triamcinolone compared to laser. The recently completed GENEVA trials showed that sustained-release dexamethasone inserts (Ozurdex ${ }^{\circledR}$; Allergan, Inc., Irvine, CA, USA) are superior to sham but drug-related adverse events (cataracts and glaucoma) frequently limit their use to the second-line therapy. ${ }^{16}$ Successful Phase III trials led to US Food and Drug Administration approval of ranibizumab and aflibercept for the treatment of BRVO-related macular edema, thereby shifting the standard of care to anti-VEGF therapy. ${ }^{9,10}$

Bevacizumab is noninferior to ranibizumab for the treatment of exudative age-related macular degeneration, ${ }^{17,18}$ but retinal vein occlusions are associated with higher intraocular VEGF concentrations, ${ }^{19}$ so equivalence of bevacizumab and ranibizumab for vein occlusions cannot be automatically assumed. In the first MARVEL report, we found a -2.5 $(95 \%$ CI -8.0 to +5.0$)$ letter difference (bevacizumab ranibizumab) between the treatment groups at the 6-month primary end point. At the 12-month secondary end point, the visual benefits of PRN bevacizumab and ranibizumab had been sustained, but the noninferiority of bevacizumab still could not be demonstrated ( -2.8 letters; $95 \%$ CI -7.0 to +4.0 letters). Before results of more comparative trials are published, such as the SCORE 2, comparing bevacizumab with aflibercept, physicians may elect to use bevacizumab for macular edema due to BRVO with the confidence that most patients respond favorably with excellent improvements in BCVA, but they should not assume that bevacizumab is noninferior to ranibizumab or aflibercept.
Significant improvements in VA have previously been reported with monthly bevacizumab therapy, ${ }^{20-22}$ but when injections are administered less frequently or PRN, poorer visual improvements may result $(+1.6$ lines to +3 lines). In the MARVEL trial, we chose to administer both drugs on a PRN basis after the first injection in order to minimize the treatment costs. To further reduce costs and ease the treatment burden, at 6 months, we decreased the examination frequency and modified the retreatment criteria so that injections were given only with a loss of five or more letters from the best-ever BCVA together with fluid on OCT. By extending the examination intervals to 2 months (instead of monthly), we reduced the visit burden experienced by both patients and physicians but still achieved remarkable stability (bevacizumab: +0.5 letters; ranibizumab: +0.8 letters) in BCVA.

The mean numbers of ranibizumab and bevacizumab injections in the MARVEL trial were significantly less than those seen in the BRAVO trial at both 6 months (3.2 and 3.0 vs 6 , respectively) and 12 months ( 0.35 and 0.29 vs 2.7 , respectively). ${ }^{8,9}$ Between months 6 and 12, eyes maintained their VA gains despite mild increases in CRT (ranibizumab: $+16.9 \mu \mathrm{m}$; bevacizumab: $+11.4 \mu \mathrm{m})$. These data suggest that mild increases in macular thickness $(<50 \mu \mathrm{m})$ may not necessarily decrease BCVA. With our modified retreatment criteria, $73.3 \%$ of eyes did not require injections during the final 6 months of the trial.

Laser photocoagulation for macular edema due to BRVO had been considered standard of care since the BVOS ${ }^{12}$ and SCORE trials ${ }^{15}$ but it was used as a rescue treatment in the more recent $B R A V O{ }^{8,9}$ and VIBRANT trials. ${ }^{10}$ Some physicians believe that macular laser photocoagulation may reduce the injection burden in eyes with BRVO, but its exact role has not been well defined. In the MARVEL trial, rescue laser was performed during the final 6 months because of increased macular thickening, whereas anti-VEGF injections were administered only when the VA had dropped by five or more letters. We noted an increase in the proportion of patients requiring rescue laser when the evaluation interval was extended from 1 month to 2 months ( $16.0 \%$ vs $25.3 \%$ ), suggesting that the VEGF drive persists even after a more aggressive injection regimen during the first 6 months. Nonetheless, the rescue laser frequency during the second 6 months of the MARVEL trial compares favorably to that in the BRAVO trial $(25.3 \%$ vs $23.7 \%),{ }^{9}$ suggesting that the monthly PRN injection regimen employed during the first 6 months of the MARVEL trial was remarkably durable. Our data suggest that laser photocoagulation of the macula still plays an important role in the management of BRVO, though only 
a minority of eyes actually require rescue therapy. It appears that in our population, extending the visit interval to 2 months may be an effective and safe strategy regardless of which drugbevacizumab or ranibizumab - is used. The VA results in the MARVEL trial were comparable to those achieved in BRAVO and VIBRANT trials despite the administration of considerably fewer injections. ${ }^{9,10}$ Less aggressive retreatment criteria with additional grid laser may be effective in maintaining the initial gain. Further study is warranted to determine if the results from this study can be reproduced in other populations.

\section{Conclusion}

Our study showed that PRN administration of both ranibizumab and bevacizumab effectively reduces CRT and improves BCVA in patients with macular edema due to BRVO. The modified retreatment criteria used during the second 6 months together with bimonthly evaluations may help reduce treatment costs, but further studies with this treatment regimen are needed.

\section{Acknowledgments}

This study was supported by the Hyderabad Eye Research Foundation, India. Divya Balakrishnan, Navakanth Bandi, Piyush Bansal, Vivek Dave, Sripathi Kamath, Kshitiz Kumar, Ajit B Majji, Annie Mathai, Kopal Mithal, Olubayo Kolawale, Anand Partani, Devendra Phalak, Padmaja K Rani, Rajeev P Reddy, Nidhi Relhan, Aditya Sudhalkar, Mudit Tyagi, Devendra Venkatramani, Archana Bhargava, and Sridevi Rayasam were the study group investigators. This study was presented at the American Society of Retina Specialists Annual Meeting, Vienna, Austria, on July 2015.

\section{Disclosure}

The authors report no conflicts of interest in this work.

\section{References}

1. Mitchell P, Smith W, Chang A. Prevalence and associations of retinal vein occlusion in Australia: the Blue Mountains Eye Study. Arch Ophthalmol. 1996;114(10):1243-1247.

2. Klein R, Klein BE, Moss SE, Meuer SM. The epidemiology of retinal vein occlusion: the Beaver Dam Eye Study. Trans Am Ophthalmol Soc. 2000;98:133-143.

3. Noma H, Mimura T, Yasuda K, Shimura M. Role of soluble vascular endothelial growth factor receptors-1 and -2, their ligands, and other factors in branch retinal vein occlusion with macular edema. Invest Ophthalmol Vis Sci. 2014;55(6):3878-3885.

4. Sohn HJ, Han DH, Kim IT, et al. Changes in aqueous concentrations of various cytokines after intravitreal triamcinolone versus bevacizumab for diabetic macular edema. Am J Ophthalmol. 2011;152(4):686-694.

5. Garrido-Urbani S, Bradfield PF, Lee BP, Imhof BA. Vascular and epithelial junctions: a barrier for leucocyte migration. Biochem Soc Trans. 2008;36(Pt 2):203-211.
6. Bates DO, Curry FE. Vascular endothelial growth factor increases microvascular permeability via a $\mathrm{Ca}(2+)$-dependent pathway. Am J Physiol. 1997;273(2 Pt 2):H687-H694.

7. Roberts WG, Palade GE. Increased microvascular permeability and endothelial fenestration induced by vascular endothelial growth factor. J Cell Sci. 1995;108(Pt 6):2369-2379.

8. Campochiaro PA, Heier JS, Feiner L, et al. Ranibizumab for macular edema following branch retinal vein occlusion: six-month primary end point results of a phase III study. Ophthalmology. 2010;117(6): $1102-1112$.

9. Brown DM, Campochiaro PA, Bhisitkul RB, et al. Sustained benefits from ranibizumab for macular edema following branch retinal vein occlusion: 12-month outcomes of a phase III study. Ophthalmology. 2011;118(8):1594-1602.

10. Campochiaro PA, Clark WL, Boyer DS, et al. Intravitreal aflibercept for macular edema following branch retinal vein occlusion: the 24-week results of the VIBRANT study. Ophthalmology. 2015;122(3): $538-544$.

11. Narayanan R, Panchal B, Das T, Chhablani J, Jalali S, Ali MH. A randomized, double-masked, controlled study of the efficacy and safety of intravitreal bevacizumab versus ranibizumab in the treatment of macular oedema due to branch retinal vein occlusion: MARVEL Report No. 1. Br J Ophthalmol. 2015;99(7):954-959.

12. Branch Vein Occlusion Study Group. Argon laser photocoagulation for macular edema in branch vein occlusion. Arch Ophthalmol. 1992; 110:1427-1434.

13. Jonas JB, Akkoyun I, Kamppeter B, Kreissig I, Degenring RF. Branch retinal vein occlusion treated by triamcinolone acetonide. Eye (Lond). 2005;19(1):65-71.

14. Chen SD, Sundaram V, Lochhead J, Patel CK. Intravitreal triamcinolone for the treatment of ischemic macular edema associated with branch retinal vein occlusion. Am J Ophthalmol. 2006;141(5): 876-883.

15. SCORE Study Research Group. A randomized trial comparing the efficacy and safety of intravitreal triamcinolone with standard care to treat vision loss associated with macular edema secondary to branch retinal vein occlusion: the Standard Care vs Corticosteroid for Retinal Vein Occlusion (SCORE) Study report 6. Arch Ophthalmol. 2009;127(9):1115-1128.

16. Haller JA, Bandello F, Belfort R Jr, et al; for the OZURDEX GENEVA Study Group. Randomized, sham-controlled trial of dexamethasone intravitreal implant in patients with macular edema due to retinal vein occlusion. Ophthalmology. 2010;117(6): 1134-1146.e3.

17. Comparison of Age-related Macular Degeneration Treatment Trials (CATT) Research Group; Martin DF, Maguire MG, et al. Ranibizumab and bevacizumab for treatment of neovascular age-related macular degeneration: two-year results. Ophthalmology. 2012;119(7): $1388-1398$.

18. Chakravarthy U, Harding SP, Rogers CA, et al; IVAN Study Investigators. Alternative treatments to inhibit VEGF in age-related choroidal neovascularisation: 2-year findings of the IVAN randomized controlled trial. Lancet. 2013;382(9900):1258-1267.

19. Aiello LP, Avery RL, Arrigg PG, et al. Vascular endothelial growth factor in ocular fluid of patients with diabetic retinopathy and other retinal disorders. $N$ Engl J Med. 1994;331(22):1480-1487.

20. Kreutzer TC, Alge CS, Wolf AH, et al. Intravitreal bevacizumab for the treatment of macular oedema secondary to branch retinal vein occlusion. Br J Ophthalmol. 2008;92(3):351-355.

21. Donati S, Barosi P, Bianchi M, Al Oum M, Azzolini C. Combined intravitreal bevacizumab and grid laser photocoagulation for macular edema secondary to branch retinal vein occlusion. Eur J Ophthalmol. 2012;22(4):607-614.

22. Ehlers JP, Decroos FC, Fekrat S. Intravitreal bevacizumab for macular edema secondary to branch retinal vein occlusion. Retina. 2011;31(9): $1856-1862$. 
Clinical Ophthalmology

\section{Publish your work in this journal}

Clinical Ophthalmology is an international, peer-reviewed journal covering all subspecialties within ophthalmology. Key topics include: Optometry; Visual science; Pharmacology and drug therapy in eye diseases; Basic Sciences; Primary and Secondary eye care; Patien Safety and Quality of Care Improvements. This journal is indexed on

Submit your manuscript here: http://www.dovepress.com/clinical-ophthalmology-journal

PubMed Central and CAS, and is the official journal of The Society of Clinical Ophthalmology (SCO). The manuscript management system is completely online and includes a very quick and fair peer-review system, which is all easy to use. Visit http://www.dovepress.com/ testimonials.php to read real quotes from published authors. 